\title{
A rare type of renal tumor - mucinous tubular and spindle cell carcinoma
}

\author{
Andreea Dima ${ }^{1,2}$, Anda Maria Aignătoaiei ${ }^{1,2}$, Irina-Draga Căruntu, ${ }^{\star 1,2}$, Ludmila \\ Lozneanu $^{1,3}$, Delia Gabriela Ciobanu Apostol ${ }^{1,3}$, Elena Roxana Avădănei ${ }^{1}$ \\ 1Department of Morpho-Functional Sciences, "Grigore T. Popa" University of Medicine and Pharmacy, \\ laşi, Romania, ${ }^{2}$ Department of Pathology, "Dr. C.I. Parhon" Clinical Hospital, lasi, Romania, \\ ${ }^{3}$ Department of Pathology, "Sf. Spiridon" University Emergency Hospital, lasi, Romania
}

\begin{abstract}
Mucinous tubular and spindle cell carcinoma (MTSCC) of the kidney, a rare renal cell carcinoma, is a low grade malignant tumor with histogenesis still under debate. We report the case of a 60 -years-old female, asymptomatic, with no significant personal or family history, diagnosed on routine ultrasound examination with a unilateral non-homogenous mass in the right kidney. On gross examination the tumor was solid, well circumscribed, and limited to the kidney parenchyma. Microscopically, the tumor was composed from eosinophilic small cuboidal cell arranged in small, tightly packed, parallel tubular structures, myxoid stroma and mucinous areas (PAS and Alcian Blue positive). Therefore, the differential diagnosis between MTSCC and papillary renal cell carcinoma was compulsory. The immunohistochemistry assays confirmed MTSCC as the final diagnosis, based on the intense positive reaction for CK7 and negative reaction for CD10. The present report aimed to highlight the pathological characteristics of this rare subtype of renal cell tumors and to point out the differential diagnosis - particularly with the papillary renal cell carcinoma, given the different prognosis and therapeutic approach of these two entities.
\end{abstract}

Keywords: renal carcinoma, mucinous tubular and spindle cell carcinoma, pathology, immnunohistochemistry

\section{Introduction}

Mucinous tubular and spindle cell carcinoma (MTSCC) is a rare renal cell carcinoma subtype that comprises less than $1 \%$ of the total renal tumors [1, 2]. It was added to the WHO classification of kidney tumors in 2004, described as a tumor with good prognosis [3, 4].

A case series of kidney tumors with the histopathological characteristics of this

Received: November 2015; Accepted after review: December 2015; Published: December 2015.

${ }^{*}$ Corresponding author: Prof. Dr. Irina-Draga Căruntu, MD, PhD, Department of Morpho-Functional Sciences, "Grigore T. Popa" University of Medicine and Pharmacy, 16 Universitatii Street, 700115, Iaşi, Romania,

Email: irinadragacaruntu@gmail.com diagnostic entity was firstly described in 1997 , when the authors presumed it to be a low grade malignant tumor arising from the collecting duct epithelium [5, 6]. The exact origin of MTSCC is still under debate. Even though other authors also supported it's histogenesis in the collecting ducts [7], further immunohistochemistry assays showed high expression of epithelial markers related to the distal convoluted cells [8, 9], but also many markers in common with the papillary renal cell carcinoma, which could indicate the development from the proximal tubules [1012].

It is challenging to differentiate MTSCC from other renal cell carcinoma subtypes that exhibit comparable morphologic features, but have a less favorable prognosis - namely papillary renal cell carcinoma, collecting duct 
carcinoma, metanephric adenoma or sarcomatoid carcinomas. The most confusing histopathologic similarities are noted between MTSCC and papillary renal cell carcinoma, especially the one with sarcomatoid dedifferentiation. They also share quite similar immunophenotypes, but CD10 is negative or present only in $15 \%$ of MTSCC, while positive in $80-85 \%$ of papillary renal cell carcinoma [6, 10]. Moreover, genetic studies sustain different chromosomal anomalies of these two entities: the papillary renal cell carcinoma display gains of chromosomes 7 and 17 and losses of chromosome $\mathrm{Y}$, which are not found in the MTSCC [13, 14]. This can further help to differentiate the two types of tumors.

Within this context, this case report aims to highlight the pathological characteristics of this rare subtype of renal cell tumors and to point out the differential diagnosis particularly with the papillary renal cell carcinoma, given the different prognosis and therapeutic approach of these two entities.

\section{Case report}

We herein describe the case of a 60 years old female admitted on September 2015 to the Urology Clinic of the "Dr. C.I. Parhon" Clinical Hospital lasi for surgical treatment due to renal cyst, Bosniak type IV, previously diagnosed on a routine ultrasound examination.

At her first presentation, the patient was asymptomatic, with no significant family history. Personal antecedents included high blood pressure stage III managed under medical treatment. Physical exam did not show systemic changes, and the laboratory tests revealed $E$. coli urinary infection. Imaging exams performed before surgery, respectively echography and computer tomography, indicated the presence of a round, echogenic, non-homogenous mass, with peripheral calcifications, measuring $45 / 47 \mathrm{~mm}$, situated at the lower pole of the right kidney. In addition, a left ovary cyst was identified.

Right nephrectomy was performed, with favorable post-operatory evolution.
The pathological exam was conducted in the Pathology Department of "C.I. Parhon" Hospital. On gross examination, the kidney presented increased anterior-posterior diameter $(10 / 6 / 6 \mathrm{~cm})$ and a weight of 252 grams. On cut surface we identified a solid well circumscribed nodule measuring 5/4.5/4.5 $\mathrm{cm}$, whitish, with hemorrhage foci. The tumor was placed in the lower half of the kidney, extended from the pieloureteral junction proximity to the renal capsule.

Tissue samples were fixed in 10\% formalin, embedded in paraffin blocks, sectioned at 4- $\mu \mathrm{m}$ thickness, and routinely stained with Hematoxylin-Eosin (HE).

Microscopically, the kidney parenchyma presented a tumor proliferation with tubular growth pattern. The tubular structures were elongated, small, tightly packed, arranged in parallel bands alternating with swirling disposition, suggesting in some areas a spindle cell appearance (Figure 1). The tumor cells were cuboidal and presented eosinophilic cytoplasm with one or more obvious nucleoli (Fuhrman 2) (Figure 2). The tumoral stroma was myxoid and comprised extracellular mucin areas, positive for Alcian Blue and Periodic Acid-Schiff (PAS) stains - recommended and performed after the initial examination of the routinely stained specimens (Figures 3,4). Hemorrhage areas and foamy macrophages were also identified (Figure 5). The tumor was limited to the kidney parenchyma, without the involvement of the renal capsule or the perihilar fat (stage $\mathrm{pT}_{1 \mathrm{~b}} \mathrm{~N}_{\mathrm{x}}$ ).

All the above mentioned morphological features sustained our diagnostic supposition of MTSCC. In order to confirm this diagnosis, the immunohistochemical assessment was done at the Pathology Department of "Sf. Spiridon" University Emergency Hospital, using monoclonal antibodies against cytokeratin 7 (clone RN7, Novocastra, dilution1:100) and CD10 (clone 56C6, Novocastra, dilution 1:100). The tumor cells were positive for cytokeratin 7 (CK7) (Figure 6 ), and negative for CD10 (Figure 7). The final diagnostic was MTSCC, low grade. 


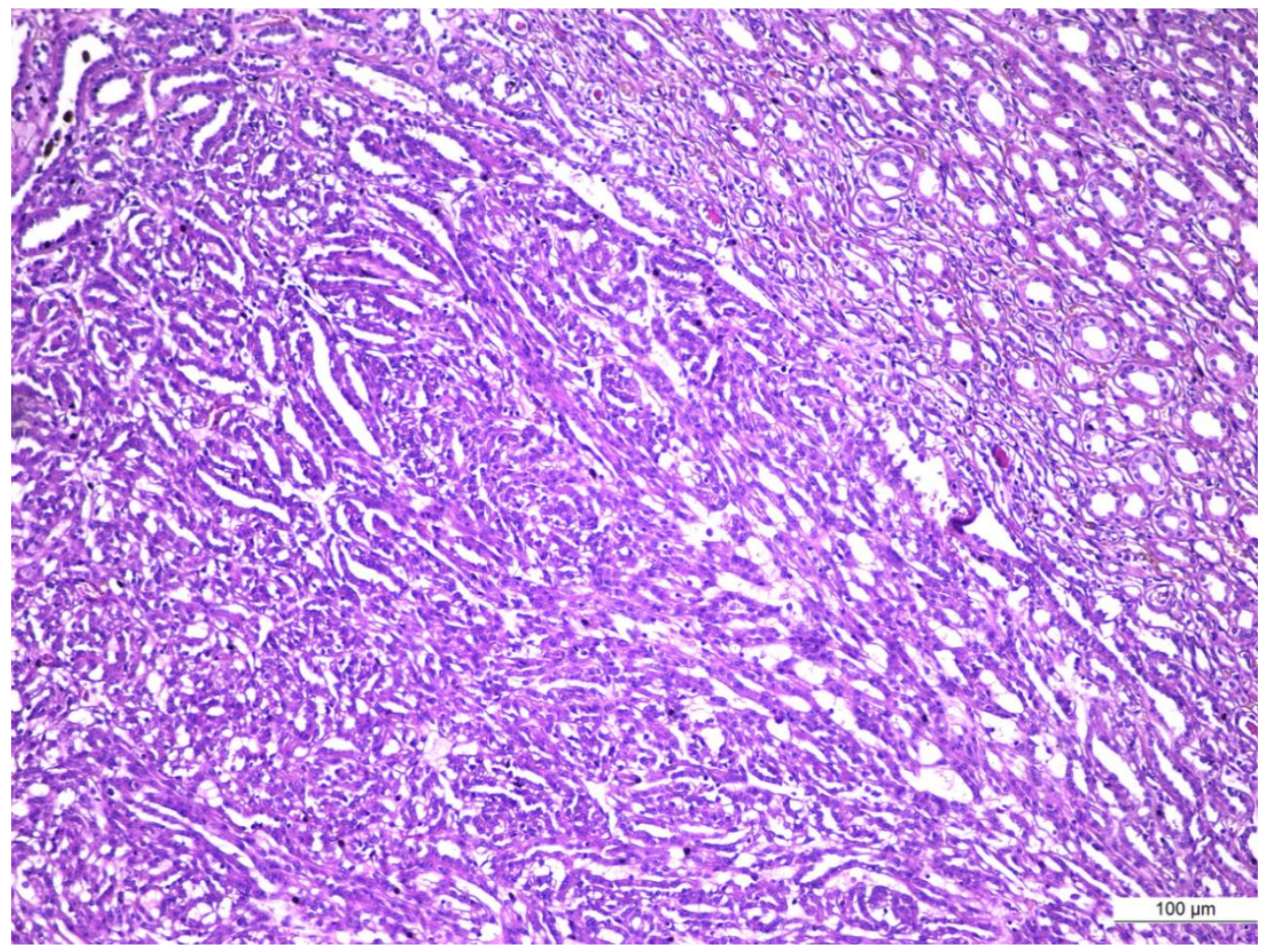

Fig. 1. Tubular pattern of the tumor proliferation, associated with the presence of a mucinous secretion (HE, x100)

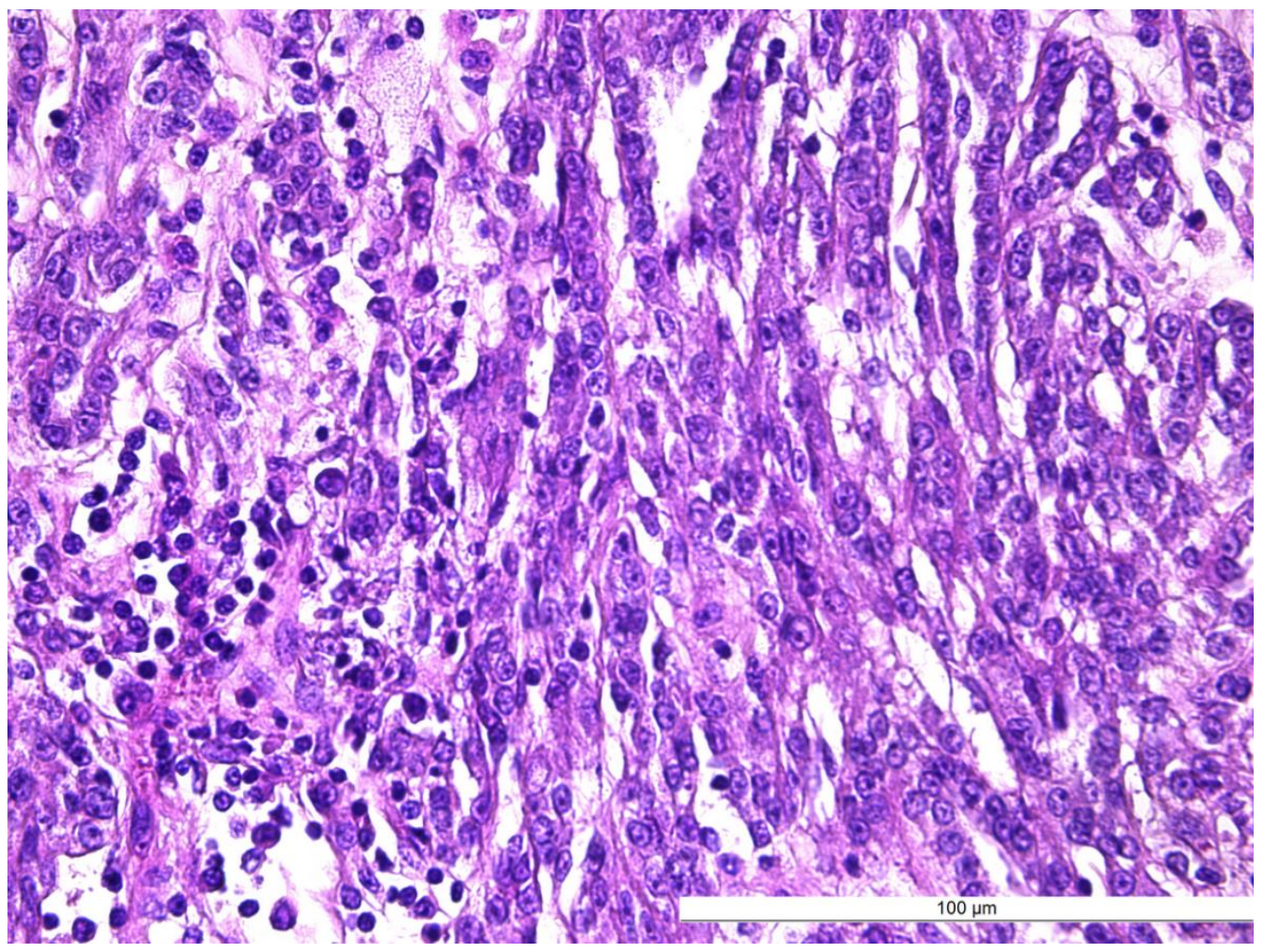

Fig. 2. Details for the morphology of the tumor cells (HE, $x 400)$ 


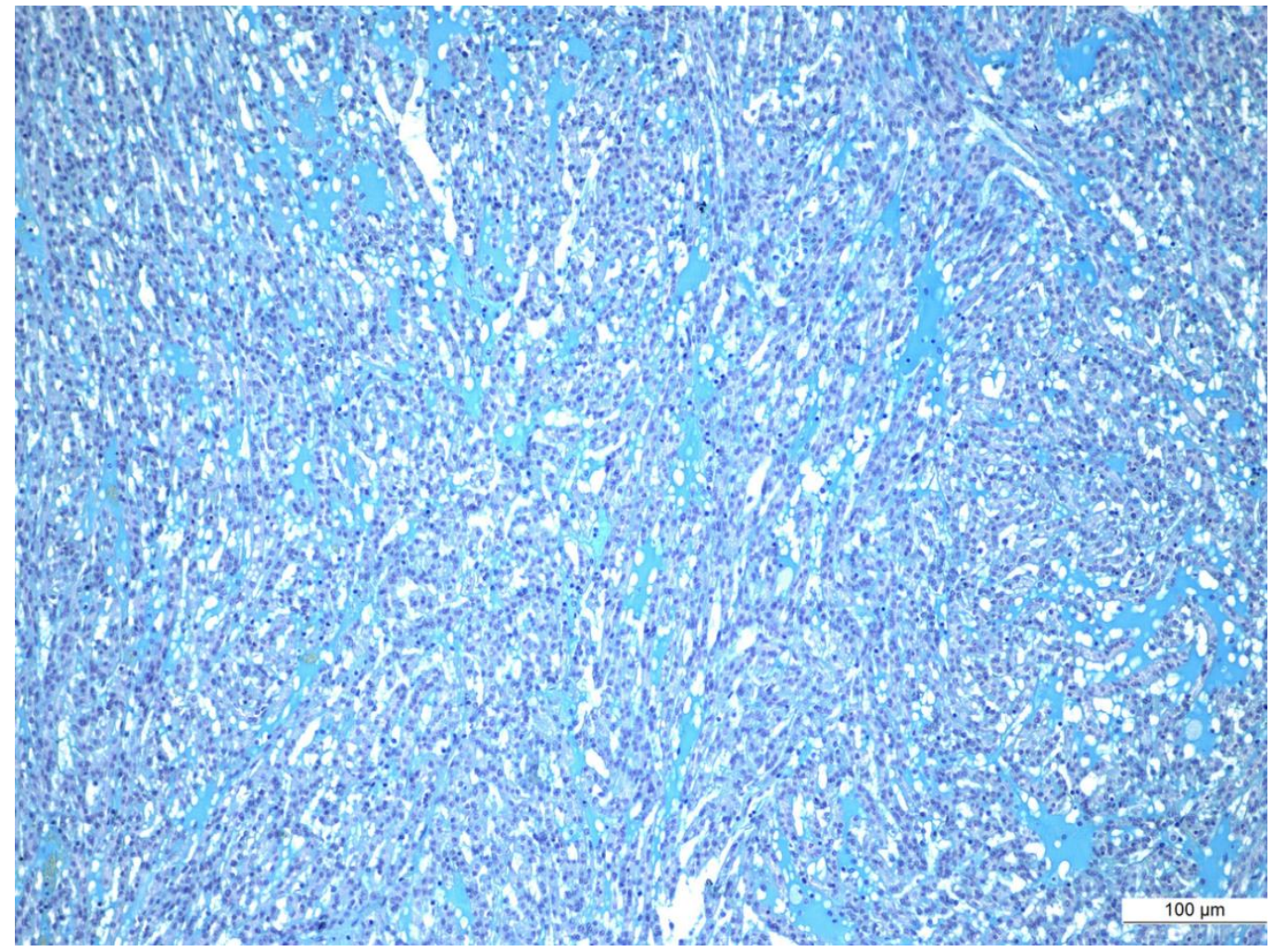

Fig. 3. Large mucin areas present within the tumor proliferation (Alcian Blue, x100)

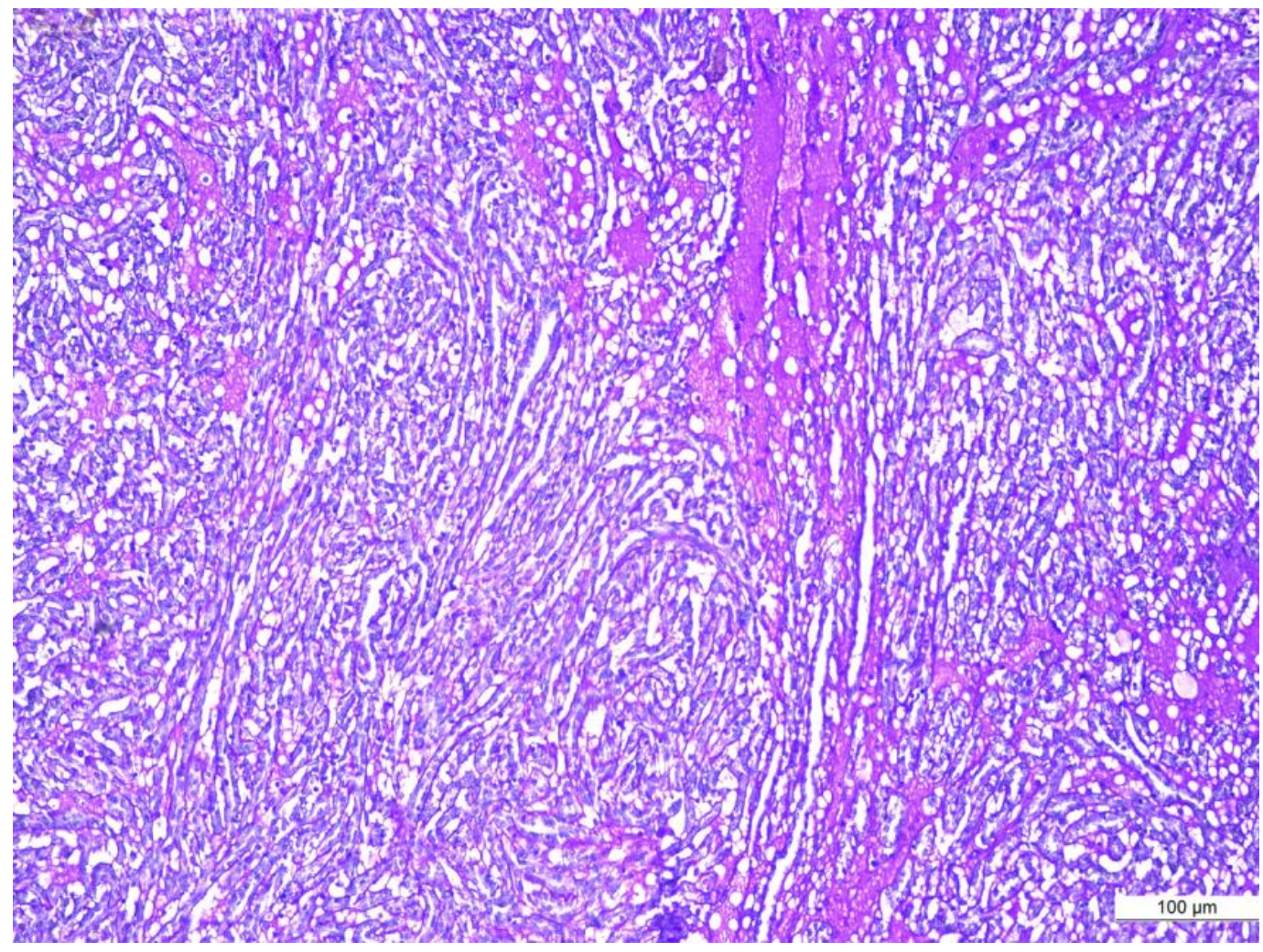

Fig. 4. Large mucin areas present within the tumor proliferation (PAS, x100) 


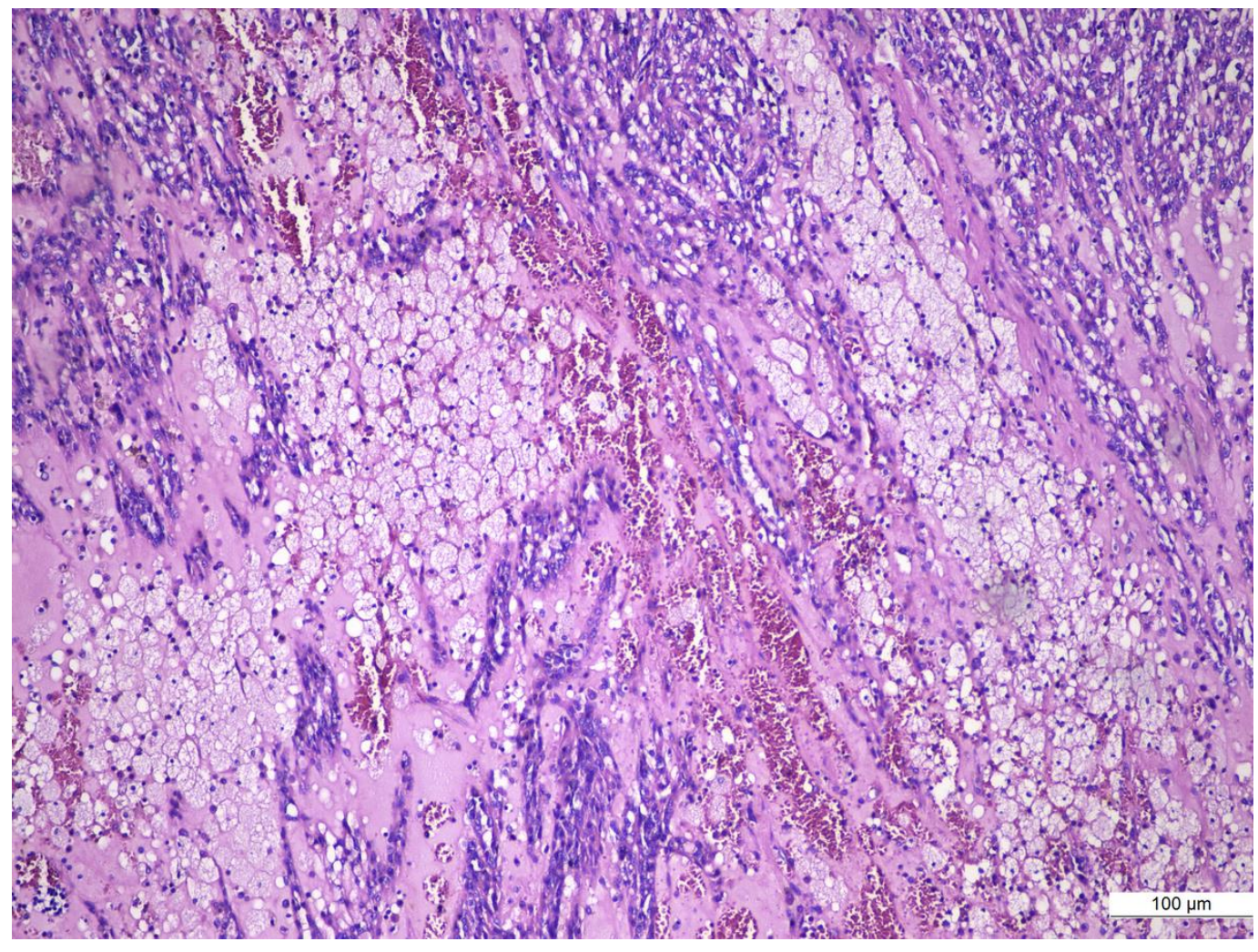

Fig. 5. Hemorrhagic zones and clusters of foamy macrophages associated with tumor proliferation (HE, x100)

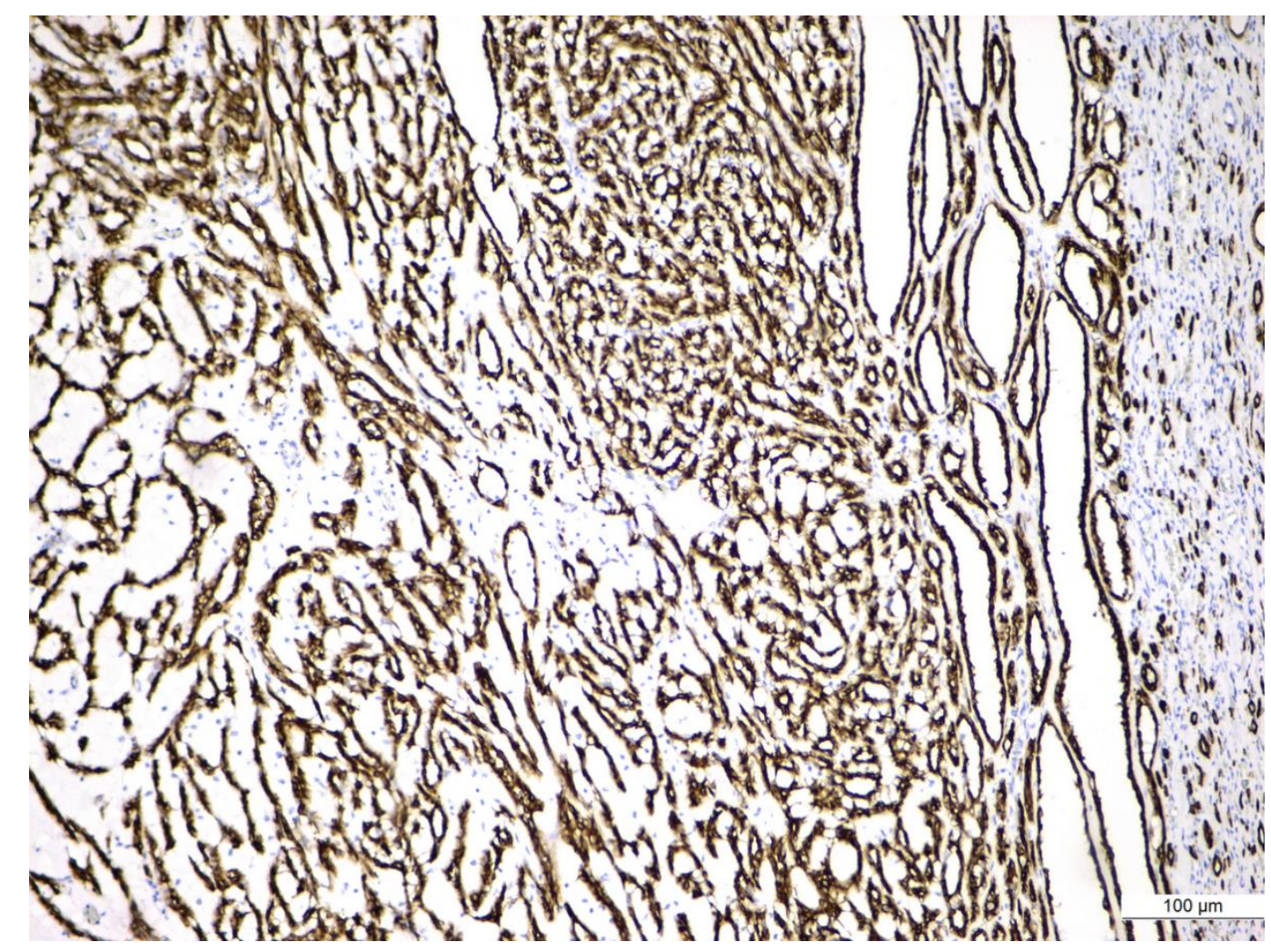

Fig. 6. Positive CK7 expression in tumor cells (IHC, Ab anti-CK7, x100) 


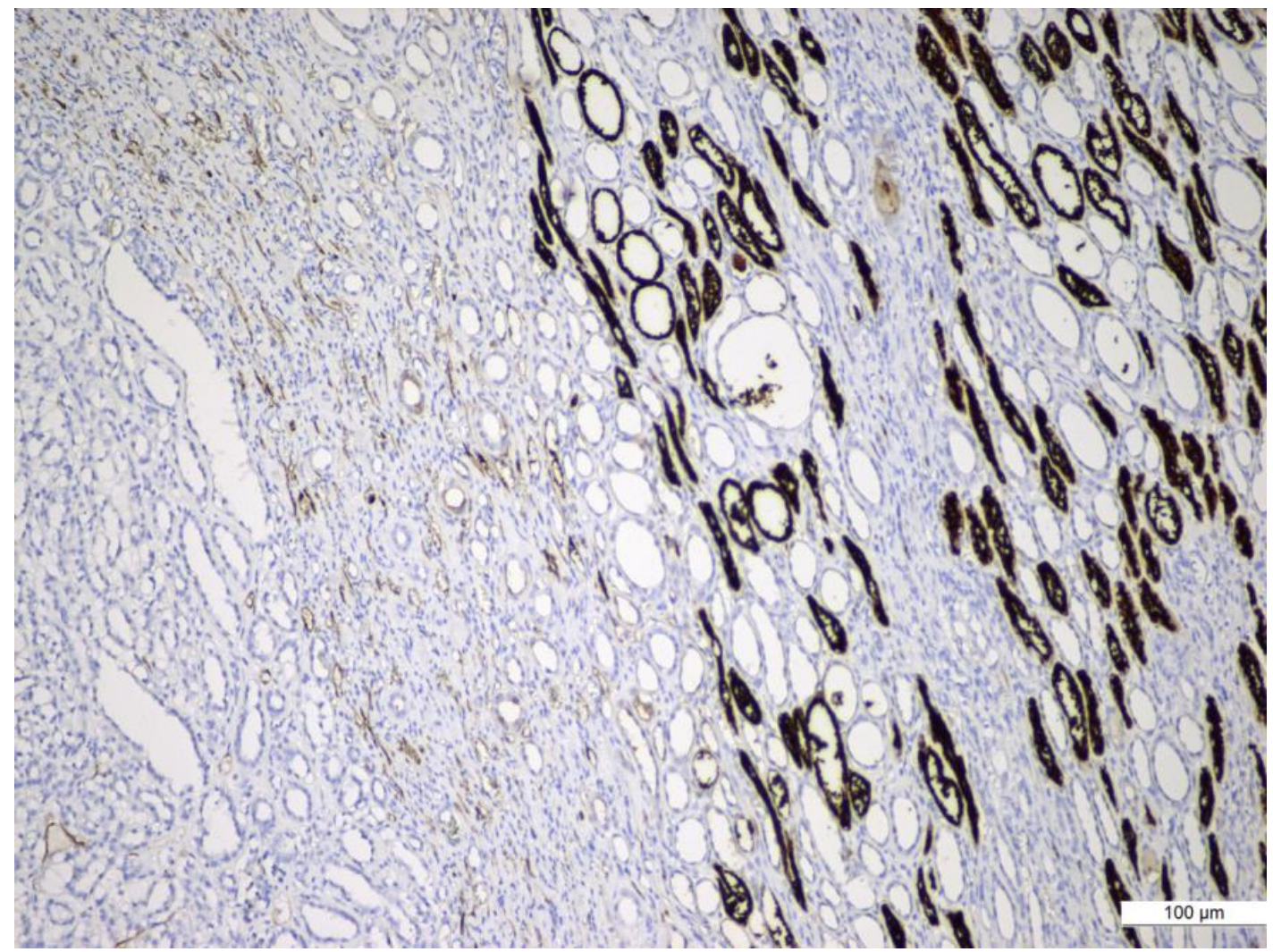

Fig. 7. Negative CD10 reaction in tumor cells (IHC, Ab anti-CD10, x100)

\section{Discussions}

Several studies on large cohorts of patients with renal tumors registered MTSCC rates ranging between $0.8 \%$ and $1.8 \%$ of the cases included [15-17]. Given this fact, MTSCC has usually been presented in the mainstream publication as single cases or case series. To the best of our knowledge, between 1997 and 2014 the total number of the reported MTSCC cases was approximately $100[6,18]$. Recently though, new data on the genetic anomalies and morphologic variant of MTSCC, in comparison with papillary renal cell carcinoma, were available, based on the investigation of 54 cases - the greatest MTSCC cohort analyzed till now [19].

MTSCC is obviously more frequent in females, with men versus women ratio of $1: 4$ $[6,20]$. It can occur at various ages, the patients ranging between 17-82 years old at the moment of diagnostic (mean 53 years) [6, 20]. It is generally asymptomatic, discovered incidentally during imagistic examinations; in rare cases, it can determine flank pain or hematuria [6, 20, 21].

Gross examination of the tumor renders it as a well circumscribed, nodular mass, with the greatest dimension from 2.2 to $12 \mathrm{~cm}$ (mean 6 to $7 \mathrm{~cm}$ ) $[6,20]$. Its color ranges from gray, white, tan or yellow, possible with small areas of hemorrhage or necrosis [6, 20, 22].

The classic histopathologic pattern of MTSCC comprises three main elements: (i) cuboidal cells forming closely arranged tubules, (ii) a mucinous stroma and (iii) spindle cell areas [3, 18, 23]. But the microscopic appearance of this tumor can be quite polymorphic. Two morphologic variants were described: the classic one, with abundant mucin ( $>50 \%$ on Alcian Blue staining), and the non-classic, poor-mucin variant $(<10 \%$ on Alcian Blue staining) [24]. Furthermore, there were reported some particular histologic features, like foamy macrophages, papillae formation, focal clear cells in tubules, necrosis, oncocytic tubules, abundant small vacuoles, heterotopic bone formation, psammomatous 
calcifications, nodular growth with lymphocytic cuffing [24].

Even though most of the MTSCC are low grade tumors with indolent behavior, there were reported cases with high-grade aspect, that exhibit high cyto-nuclear pleomorphism and proliferative index [25, 26]. Rarely, this tumor can give rise to metastasis, in association with sarcomatoid differentiation [27-29]. Surprisingly, there were also reported two cases of MTSCC with low-grade pattern that disseminated to secondary locations to form metastasis [30, 31].

The immunoprofile of MTSCC has been deeply studied, showing a great deal of variability. In a case series of four tumors, the authors reported intense and diffuse positivity for CK7, variable expression of epithelial membrane antigen (EMA), vimentin, S100, Ulex europaeus antigen, high-molecular weight CK, CK 8, CK 18 and CK19, and diffuse negativity for carcinoembryonic antigen (CEA), CD15, CD34, desmin, actin, CK10, CK20 and HMB45 [15]. Another paper based on a 15 cases series reported results that indicate a distal tubular cell profile (positive expression of EMA, AE1/AE3, CK7, CK19, Ecadherin, alpha-methylacyl-CoA racemase (AMACR), and negative for CD10) [8]. Also, in a comparative study of 27 cases of MTSCC and 20 cases of papillary renal cell carcinoma, the two type of tumors exhibit similar expression of AMACR (93\% versus 95\%), CK7 (81\% versus $65 \%)$, EMA (95\% versus $88 \%)$, high molecular weight cytokeratin (HMWK) (15\% versus 15\%), and c-kit (5\% versus $18 \%$ ), with CD10 being the only marker that showed a significant difference of expression (15\% versus $80 \%$ ) [10]. A more recent, similar, comparative research between MTSCC and papillary renal cell carcinoma ( 9 , respectively 10 cases) confirmed the importance of CD10 in the differential diagnosis of the two entities [32]. Curiously, MTSCC also could present positive expression of neuroendocrine markers (neuron-specific enolase, chromogranin, and synaptophysin), of still uncertain signification [9, 33].

Our case illustrated a typical patient with MTSCC, according to the female predominance, the average age at diagnosis and the clinically silent behavior of the tumor.
On gross examination, the tumor's dimension was little below the average size reported in the literature. On microscopic examination, the tubular structures formed by small, cuboidal cells, in association with the foci of foamy macrophages amongst them, were confusingly similar with the papillary structures, lined by the same type of epithelium, with foamy macrophages inside their axes that characterize the papillary renal cell carcinoma. Our attention was drawn by the myxoid stroma, with a significant amount of pale, amorphous material (on HE stain), and also by the spindle cell areas. On close examination of the nuclei, with $10 x$ magnification, we observed finely granular chromatin and inconspicuous nucleoli (Fuhrman 2). We thought that these elements are suggestive for the MTSCC and performed ancillary tests for differential diagnosis, namely PAS and Alcian Blue stains for mucin identification and CK7 and CD10 for immunophenotyping. The pale, amorphous areas identified on HE stained positive on PAS and Alcian Blue, demonstrating the presence of a significant amount of mucus in the tumor stroma. The immunohistochemistry exam further supported the diagnosis of MTSCC, showing positive expression of $\mathrm{CK} 7$ and negative expression of CD10.

Thus, we report the case of a low grade (Fuhrman 2), classic histologic variant of MTSCC (with abundant mucin), associating an unusual histologic feature (foci of foamy macrophages) and an immunohistochemistry profile corresponding with the data available in the literature.

\section{Conclusion}

Given the polymorphic histologic appearance of this tumor subtype, its correct identification can be a challenge for pathologists. Even though it is rarely encountered, MTSCC should be considered when evaluating an atypical renal tumor, because it generally has a much better prognosis and a different therapeutic approach than the other renal tumors with similar histologic features. 


\section{References}

1. Shanbhogue AK, Vikram R, Paspulati RM, et al. Rare $(<1 \%)$ histological subtypes of renal cell carcinoma: an update. Abdom Imaging 2012; 37(5):861-72.

2. Cao $\mathrm{W}$, Huang $\mathrm{B}$, Fei $\mathrm{X}$, et al. Clear cell changes in mucinous tubular and spindle cell carcinoma: cytoplasmic pallor/clearing within tubules, vacuoles or hybrid conventional clear cell carcinoma of kidney?. Int J Clin Exp Pathol 2014; 7(7):4350-4358.

3. Srigley J. Mucinous tubular and spindle cell carcinoma. In: Eble J, Sauter G, Epstein J, Sesterhenn I (eds). Pathology and Genetics of Tumours of the Urinary System and Male Genital Organs. Lyon: IARC Press, 2004.

4. Lopez-Beltran A, Carrasco JC, Cheng L, et al. 2009 update on the classification of renal epithelial tumors in adults. Int $J$ Urol 2009; 16(5):432-443.

5. MacLennan GT, Farrow GM, Bostwick DG. Low-grade collecting duct carcinoma of the kidney: report of 13 cases of low-grade mucinous tubulocystic renal carcinoma of possible collecting duct origin. Urology 1997; 50(5):679-684.

6. Sun $\mathrm{N}, \mathrm{Fu} \mathrm{Y}$, Wang $\mathrm{Y}$, et al. Mucinous tubular and spindle cell carcinoma of the kidney: A case report and review of the literature. Oncol Lett 2014; 7(3):811-814.

7. Rakozy C, Schmahl GE, Bogner S, Störkel S. Low-grade tubular-mucinous renal neoplasms: morphologic, immunohistochemical, and genetic features. Mod Pathol 2002; 15(11):1162-1171.

8. Ferlicot $\mathrm{S}$, Allory $\mathrm{Y}$, Compérat $\mathrm{E}$, et al. Mucinous tubular and spindle cell carcinoma: a report of 15 cases and a review of the literature. Virchows Arch 2005; 447(6):978983.

9. Jung SJ, Yoon HK, Chung JI, et al. Mucinous tubular and spindle cell carcinoma of the kidney with neuroendocrine differentiation: report of two cases. Am J Clin Pathol 2006; 125(1):99-104.

10. Paner GP, Srigley JR, Radhakrishnan A, et al. Immunohistochemical analysis of mucinous tubular and spindle cell carcinoma and papillary renal cell carcinoma of the kidney: significant immunophenotypic overlap warrants diagnostic caution. Am J Surg Pathol 2006; 30(1):13-19.

11. Shen SS, Ro JY, Tamboli $P$, et al. Mucinous tubular and spindle cell carcinoma of kidney is probably a variant of papillary renal cell carcinoma with spindle cell features. Ann Diagn Pathol 2007; 11(1):13-21.

12. Chander $B$, Bharti $R$, Preet $K$, Deb $P$. Mucinous tubular and spindle cell carcinoma of kidney: A case report of an unusual tumor. $J$ Cancer Res Ther 2015; 11 (3):659.

13. Cossu-Rocca P, Eble JN, Delahunt B, et al. Renal mucinous tubular and spindle carcinoma lacks the gains of chromosomes 7 and 17 and losses of chromosome $Y$ that are prevalent in papillary renal cell carcinoma. Mod Pathol 2006; 19(4):488-493.

14. Brandal $P$, Lie AK, Bassarova $A$, et al. Genomic aberrations in mucinous tubular and spindle cell renal cell carcinomas. Mod Pathol 2006; 19(2):186-194.

15. Arias LF, Blanco J, Hernández $S$, et al. Immunohistochemical profile and clinical features of mucinous tubular and spindle renal cell carcinoma. Actas Urol Esp 2006; 30(7):649-654.

16. Guazzoni G, Cestari A, Buffi N, et al. Oncologic results of laparoscopic renal cryoablation for clinical T1a tumors: 8 years of experience in a single institution. Urology 2010; 76(3):624-629.

17. Kim SH, Yang HK, Moon KC, Lee ES. Localized non-conventional renal cell carcinoma: prediction of clinical outcome according to histology. Int $J$ Urol 2014; 21(4):359-364.

18. Wang $\mathrm{H}$, Xie J, Lu C, Zhang D, Jiang J. Renal mucinous tubular and spindle cell carcinoma: report of four cases and literature review. Int $J$ Clin Exp Pathol 2015; 8(3):3122-3126.

19. Peckova $K$, Martinek $P$, Sperga $M$, et al. Mucinous spindle and tubular renal cell carcinoma: analysis of chromosomal aberration pattern of low-grade, high-grade, and overlapping morphologic variant with papillary renal cell carcinoma. Ann Diagn Pathol 2015; 19(4):226-231.

20. Zhao M, He X, Teng X. Mucinous tubular and spindle cell renal cell carcinoma: a review of clinicopathologic aspects. Diagn Pathol 2015; 10:168. DOI 10.1186/s13000-015-0402-1

21. Grigore A, Toma L, Stoicea $M$, et al. Rare renal tumor--mucinous tubular and spindle cell carcinoma. Rom J Morphol Embryol 2012; 53(1):167-171.

22. Yang G, Breyer BN, Weiss DA, MacLennan GT. Mucinous tubular and spindle cell carcinoma of the kidney. J Urol 2010; 183(2):738-739. 
23. Crumley SM, Divatia M, Truong $L$, et al. Renal cell carcinoma: evolving and emerging subtypes. World J Clin Cases 2013; 1(9): 262275.

24. Fine SW, Argani $P$, DeMarzo $A M$, et al. Expanding the histologic spectrum of mucinous tubular and spindle cell carcinoma of the kidney. Am J Surg Pathol 2006; 30(12):1554-1560.

25. Kuroda $\mathrm{N}$, Hes $\mathrm{O}$, Michal $\mathrm{M}$, et al. Mucinous tubular and spindle cell carcinoma with Fuhrman nuclear grade 3: a histological, immunohistochemical, ultrastructural and FISH study. Histol Histopathol 2008; 23(12):1517-1523.

26. Song ZG, Liu AJ, Gao J, et al. Clinical and pathologic features of renal mucinous tubular and spindle cell carcinoma. Zhonghua Bing $\mathrm{Li}$ Xue Za Zhi. 2011; 40(7):440-443.

27. Simon RA, di Sant'agnese PA, Palapattu GS, et al. Mucinous tubular and spindle cell carcinoma of the kidney with sarcomatoid differentiation. Int J Clin Exp Pathol 2008; 1(2):180-184.

28. Arafah M, Zaidi SN. Mucinous tubular and spindle cell carcinoma of the kidney with sarcomatoid transformation. Saudi J Kidney Dis Transpl 2013; 24(3):557-560.

29. Dhillon J, Amin MB, Selbs E, et al. Mucinous tubular and spindle cell carcinoma of the kidney with sarcomatoid change. Am J Surg Pathol 2009; 33(1):44-49.

30. Ursani NA, Robertson AR, Schieman SM, et al. Mucinous tubular and spindle cell carcinoma of kidney without sarcomatoid change showing metastases to liver and retroperitoneal lymph node. Hum Pathol 2011; 42(3):444-448.

31. Thway K, du Parcq J, Larkin JM, et al. Metastatic renal mucinous tubular and spindle cell carcinoma. Atypical behavior of a rare, morphologically bland tumor. Ann Diagn Pathol 2012; 16(5):407-410.

32. Sarsik B, Sımşır A, Karaarslan S, Sen S. Mucinous tubular and spindle cell carcinoma of kidney and problems in diagnosis. Turk Patoloji Derg 2011; 27(2):116-126.

33. Kuroda N, Hes O, Miyazaki E, et al. Frequent expression of neuroendocrine markers in mucinous tubular and spindle cell carcinoma of the kidney. Histol Histopathol 2006; 21(1):710. 